\title{
Response to comment on: Nathan DM, Buse JB, Davidson MB et al (2006) Management of hyperglycaemia in type 2 diabetes: a consensus algorithm for the initiation and adjustment of therapy. A consensus statement from the American Diabetes Association and the European Association for the Study of Diabetes. Diabetologia 49:1711-1721
}

\author{
E. Ferrannini
}

Received: 19 February 2007 / Accepted: 20 February 2007 / Published online: 6 April 2007

(C) Springer-Verlag 2007

To the Editor: In their letter to Diabetologia, Drs Slama, Balkau and Valensi correctly observe that the European Association for the Study of Diabetes (EASD) — an association of individuals with an interest in the study of diabetes - has recently deviated from its traditional policy of abstinence from guidelines and statements [1]. The (hopefully) understandable background to this move is the mounting pressure to 'translate' basic science into integrated physiology, laboratory findings into clinical correlates, and medical science into clinical practice, which I am sure Slama and colleagues have experienced themselves at some point in their daily activities. Technically, however, all three recent statements are the product of ad hoc appointed committees of experts, who have individually signed their statement and assumed responsibility for its contents. Admittedly, a stratagem for the EASD not to endorse issues in an anonymous and normative tenor, as per American Diabetes Association (ADA) and European Society of Cardiology policy, but arguably an interesting experiment in fostering medical discourse.

With regard to the contradictions and lack of harmonisation, here follows my response, which as my colleagues can guess, does not necessarily represent the position of the EASD.

E. Ferrannini $(\bowtie)$

Department of Internal Medicine, University of Pisa,

Via Roma, 67,

Pisa 56126, Italy

e-mail: ferranni@ifc.cnr.it
First, the ADA/EASD statement on the metabolic syndrome [2] was just what the title said-a critical reappraisal of the construct and its implications. It was neither in the text nor in the authors' minds that the syndrome should be banned or suppressed; rather, there was, and still is, a need for further, more focused research. For example, Slama and colleagues assert that the presence of the syndrome may add to classical scores in estimating 10 -year risk of cardiovascular mortality under 5\% [1]. This finding, possibly triggered by the ADA/EASD position, is neither general nor generalisable [3], and falls short of proving that the syndrome is a better risk predictor than its components. Also, despite having been quickly granted a disease code in the US (International Classification of Diseases, 9th revision, clinical modification [ICD-9-CM] code 277.7; available from http://www.cdc.gov/nchs/about/ major/dvs/icd9des.htm, last accessed in March 2007), the metabolic syndrome was very rarely recorded on hospital discharge or records of outpatient visits in 2002-2003 [4].

Second, my reading of the literature, old and new, is that the $2 \mathrm{~h}$ glucose concentration predicts incident diabetes (including type 1 diabetes [5]) better than, and independently of, the fasting plasma glucose concentration, and is associated with both microvascular and macrovascular complications. The recommendation that the OGTT 'has a minimal place, if any, in the diagnosis of diabetes' is unfounded, nowhere to be read in the updated report of the Expert Committee on the Diagnosis and Classification of Diabetes Mellitus [6] and far from universally accepted. My impression is that the OGTT is already widely employed as a 
confirmatory test and to screen high-risk groups. The most cost-effective use of glucose testing for screening populations, on the other hand, is a different matter, and one that could be critically examined by the EASD/ADA panel.

Third, in my view, the ADA/EASD consensus algorithm [7] is justifiably conservative. It prudently recalls that 'one clinical trial examining acarbose...showed an unexpected reduction in severe CVD [cardiovascular disease] outcomes' and that drugs that more specifically address post-prandial glucose excursions (pramlintide, exenatide, $\alpha$-glucosidase inhibitors and the glinides) 'may be appropriate choices in selected patients'. Here again is an area in which research is ongoing and the evidence is inconclusive. In addition, recommending drug use in a rigid hierarchy is probably not a good idea for several reasons. Even from panelists entirely free of bias ('For Brutus is an honourable man; so are they all, all honourable men'. [8]), detailed guidelines on pharmacological treatment are likely to ignite clinical controversy (drug A is probably better than drug B), promote expensive clinical trials (is drug $\mathrm{A}$ better than drug $\mathrm{B}$ ?), fuel marketing guerrillas (drug A is definitely better than drug B), and feed into stolid reimbursement schemes (can use only drug A).

The general practitioner, the diabetologist and the cardiologist should be harmonised but perhaps not homogenised, i.e. flattened down to a standard that others think best for each and all. As long as we are still given the option, we should stick to well-informed clinical judgement as the best service we can offer the individual patient or the community.

\section{References}

1. Slama G, Balkau B, Valensi P (2007) Comment on: Nathan DM, Buse JB, Davidson MB et al (2006) Management of hyperglycaemia in type 2 diabetes: a consensus algorithm for the initiation and adjustment of therapy. A consensus statement from the American Diabetes Association and the European Association for the Study of Diabetes. Diabetologia 49:1711-1721 DOI 10.1007/s00125-007-0669-1

2. Kahn R, Buse J, Ferrannini E, Stern M (2005) The metabolic syndrome: time for a critical appraisal: joint statement from the American Diabetes Association and the European Association for the Study of Diabetes. Diabetologia 48:1684-1699

3. Ford ES (2005) Risks for all-cause mortality, cardiovascular disease, and diabetes associated with the metabolic syndrome: a summary of the evidence. Diabetes Care 28:1769-1778

4. Ford ES (2005) Rarer than a blue moon: the use of a diagnostic code for the metabolic syndrome in the U.S. Diabetes Care 28:1808-1809

5. Sosenko JM, Palmer JP, Greenbaum CJ et al (2007) Diabetes Prevention Trial-Type 1 Study Group. Increasing the accuracy of oral glucose tolerance testing and extending its application to individuals with normal glucose tolerance for the prediction of type 1 diabetes: the Diabetes Prevention Trial-Type 1. Diabetes Care 30:38-42

6. Expert Committee on the Diagnosis and Classification of Diabetes Mellitus (2003) Report of the Committee on the Diagnosis and Classification of Diabetes Mellitus. Diabetes Care 26(Suppl 1):S5-S20

7. Nathan DM, Buse JB, Davidson MB et al (2006) Management of hyperglycaemia in type 2 diabetes: a consensus algorithm for the initiation and adjustment of therapy. A consensus statement from the American Diabetes Association and the European Association for the Study of Diabetes. Diabetologia 49:1711-1721

8. Shakespeare W (ca. 1595) Julius Caesar. Act III, Scene 2 